\title{
Ultrafast fluorescence resonance energy transfer in a bile salt aggregate: Excitation wavelength dependence
}

\author{
UJJWAL MANDAL, SUBHADIP GHOSH, DIBYENDU KUMAR DAS, \\ ANIRUDDHA ADHIKARI, SHANTANU DEY and KANKAN BHATTACHARYYA* \\ Physical Chemistry Department, Indian Association for the Cultivation of Science, Jadavpur, \\ Kolkata 700032 \\ e-mail: pckb@mahendra.iacs.res.in
}

\begin{abstract}
Fluorescence resonance energy transfer (FRET) from Coumarin 153 (C153) to Rhodamine 6G (R6G) in a secondary aggregate of a bile salt (sodium deoxycholate, NaDC) is studied by femtosecond up-conversion. The emission spectrum of $\mathrm{C} 153$ in NaDC is analysed in terms of two spectra-one with emission maximum at $480 \mathrm{~nm}$ which corresponds to a non-polar and hydrophobic site and another with maximum at $\sim 530 \mathrm{~nm}$ which arises from a polar hydrophilic site. The time constants of FRET were obtained from the rise time of the emission of the acceptor (R6G). In the NaDC aggregate, FRET occurs in multiple time scales - 4 ps and 3700 ps. The 4 ps component is assigned to FRET from a donor (D) to an acceptor $(\mathrm{A})$ held at a close distance $\left(R_{\mathrm{DA}} \sim 17 \AA\right)$ inside the bile salt aggregate. The 3700 ps component corresponds to a donor-acceptor distance $\sim 48 \AA$. The long (3700 ps) component may involve diffusion of the donor. With increase in the excitation wavelength $\left(\lambda_{\mathrm{ex}}\right)$ from 375 to $435 \mathrm{~nm}$, the relative contribution of the ultrafast component of FRET ( $\sim 4 \mathrm{ps})$ increases from 3 to $40 \%$ with a concomitant decrease in the contribution of the ultraslow component ( $\sim 3700 \mathrm{ps})$ from 97 to $60 \%$. The $\lambda_{\text {ex }}$ dependence is attributed to the presence of donors at different locations. At a long $\lambda_{\text {ex }}(435 \mathrm{~nm})$ donors in the highly polar peripheral region are excited. A short $\lambda_{\mathrm{ex}}(375 \mathrm{~nm})$ 'selects' donor at a hydrophobic location.
\end{abstract}

Keywords. Bile salt; excitation wavelength dependence; femtosecond; FRET.

\section{Introduction}

Bile salts are biologically important natural surfactant molecules and play an important role in biliary secretion and solubilization of cholesterol, lipid, bilirubin, fat-soluble vitamins and many other species in living organisms. ${ }^{1}$ The bile salt, sodium deoxycholate consists of a convex hydrophobic surface (the steroid ring) and a concave hydrophilic surface (hydroxyl groups and carboxylate ions). In a slightly alkaline medium $(\mathrm{pH}>7.5), \mathrm{NaDC}$ displays two critical micellar concentrations $\left(\mathrm{CMC}_{1}\right.$ and $\left.\mathrm{CMC}_{2}\right)$ at 10 and $60 \mathrm{mM}$, respectively. At a lower concentration $(\sim 10 \mathrm{mM})$ bile salt forms a primary aggregate with the polar face (hydroxyl group and ions) pointing outwards (scheme $2 a){ }^{\text {la }}$ At a sufficiently higher concentration $(>60 \mathrm{mM})$, the secondary aggregates are formed. ${ }^{1,2}$ According to small angle neutron scattering (SANS) studies, the secondary aggregate is a long $(\sim 40 \AA)$ cylinder with a central water filled tunnel with radius $\sim 8 \AA$ (scheme $2 b$ ). ${ }^{2}$ The microenvironment and binding dynamics of many fluores-

\footnotetext{
*For correspondence
}

cent probes in different sites of a bile salt aggregate has been studied extensively. ${ }^{3,4}$

In the present work, we report on fluorescence resonance energy transfer (FRET) between a donor (coumarin 153, C153) and an acceptor (rhodamine 6G, R6G) inside the secondary aggregate of NaDC. According to the Forster model, the rate of FRET is inversely proportional to the sixth power of distance $\left(R_{\mathrm{DA}}\right)$ between the donor $(D)$ and the acceptor $(A)^{5,6}$ As a result, FRET between a donor and an acceptor held at close proximity in a nanocavity occurs in ultrafast time scale $(\sim$ a few ps). The main interest on FRET in confined environment stems from their important role in many biological processes. ${ }^{5}$ Most recent applications of FRET include single molecule studies in protein folding, ${ }^{5 b, c}$ in polymers, ${ }^{5 e}$ and in nanoparticles. ${ }^{5 f}$

Most biological systems are heterogeneous on molecular length scale. In such a system, the donor or the acceptor may reside in drastically different environments. ${ }^{6,7}$ The absorption and emission spectra of the donor (C153) depends strongly on the polarity $^{9}$ and thus, varies markedly with different 
locations. Both the donor $(\mathrm{C} 153)$ and the acceptor (R6G) bind strongly to the NaDC aggregate. In the case of the cationic acceptor (R6G), binding to the anionic $\mathrm{NaDC}$ aggregate originates mainly from electrostatic and also from hydrophobic interaction. The neutral donor (C153) is sparingly soluble in water and much more soluble in non-polar media. Binding of $\mathrm{C} 153$ to $\mathrm{NaDC}$ is mainly governed by hydrophobic interactions.

In order to explore FRET in different regions of the bile salt aggregate, we made use of the excitation wavelength $\left(\lambda_{\mathrm{ex}}\right)$ dependence of the spectra of the donor (C153). Excitation at a shorter wavelength ('blue edge') selects the donor (C153) residing in a relatively non-polar ('buried') environment and gives rise to a blue shifted emission spectrum. On the contrary, excitation at a longer wavelength ('red edge') selects the probe in a relatively polar ('exposed') site and gives rise to a red shifted emission spectrum. This phenomenon of red shift of emission maximum with increase in $\lambda_{\text {ex }}$, is known as the red edge excitation shift (REES) ${ }^{6-8}$ Excitation wavelength $\left(\lambda_{\mathrm{ex}}\right) \mathrm{de}-$ pendence of FRET is relatively less explored. Very recently, we have demonstrated this for a micelle, ${ }^{6 a}$ gel $^{6 \mathrm{a}}$ and reverse micelle. ${ }^{6 \mathrm{~b}}$ In this work, we show that FRET in the interior of a secondary aggregation of bile salt, $\mathrm{NaDC}$ exhibits marked dependence on excitation wavelength $\left(\lambda_{\mathrm{ex}}\right)$.

\section{Experimental}

Laser grade coumarin 153 (C153, scheme la) and Rhodamine 6G (R6G, scheme $1 \mathrm{~b}$ ) were purchased from Exciton. Bile salt, sodium deoxycholate (NaDC scheme 2) was purchased form Aldrich and used without further purification. In this experiment we used an aqueous solution of $\mathrm{NaDC}$ of concentration $105 \mathrm{mM}$. Donor (C153) and acceptor (R6G) concentrations were kept fixed at $40 \mu \mathrm{M}$. The steady state absorption and emission spectra were recorded in a Shimadzu UV-2401 spectrophotometer and a Spex FluoroMax-3 spectrofluorimeter, respectively.

In our femtosecond upconversion set up (FOG 100, CDP), the sample was excited at 375,405 and $435 \mathrm{~nm}$. Briefly, the sample was excited using the second harmonic of a mode-locked Ti-sapphire laser (Tsunami, Spectra Physics) pumped by a $5 \mathrm{~W}$ Millennia (Spectra Physics). The fundamental beam was frequency doubled in a non-linear crystal (1 mm BBO, $\theta=25^{\circ}, \phi=90^{\circ}$ ). The fluorescence emitted from the sample was upconverted in a non-linear crystal $\left(0.5 \mathrm{~mm}\right.$ BBO, $\left.\theta=38^{\circ}, \phi=90^{\circ}\right)$ using a gate pulse of the fundamental beam. The upconverted light is dispersed in a monochromator and detected using photon counting electronics. A cross-correlation function obtained using the Raman scattering from ethanol displayed a full width at half maximum (FWHM) of $350 \mathrm{fs}$. The femtosecond fluorescence<smiles>O=c1cc(C(F)(F)F)c2cc3c4c(c2o1)CCCN4CCC3</smiles>

$\mathbf{C 1 5 3}$ (b)<smiles>CCCCCCN=c1cc2oc3cc(NCCCC)c(C)cc3c(-c3ccccc3C(=O)[O-])c-2cc1C</smiles>

R6G
Scheme 1. Schematic representation of Coumarin 153 (a) and Rhodamine 6G (b).
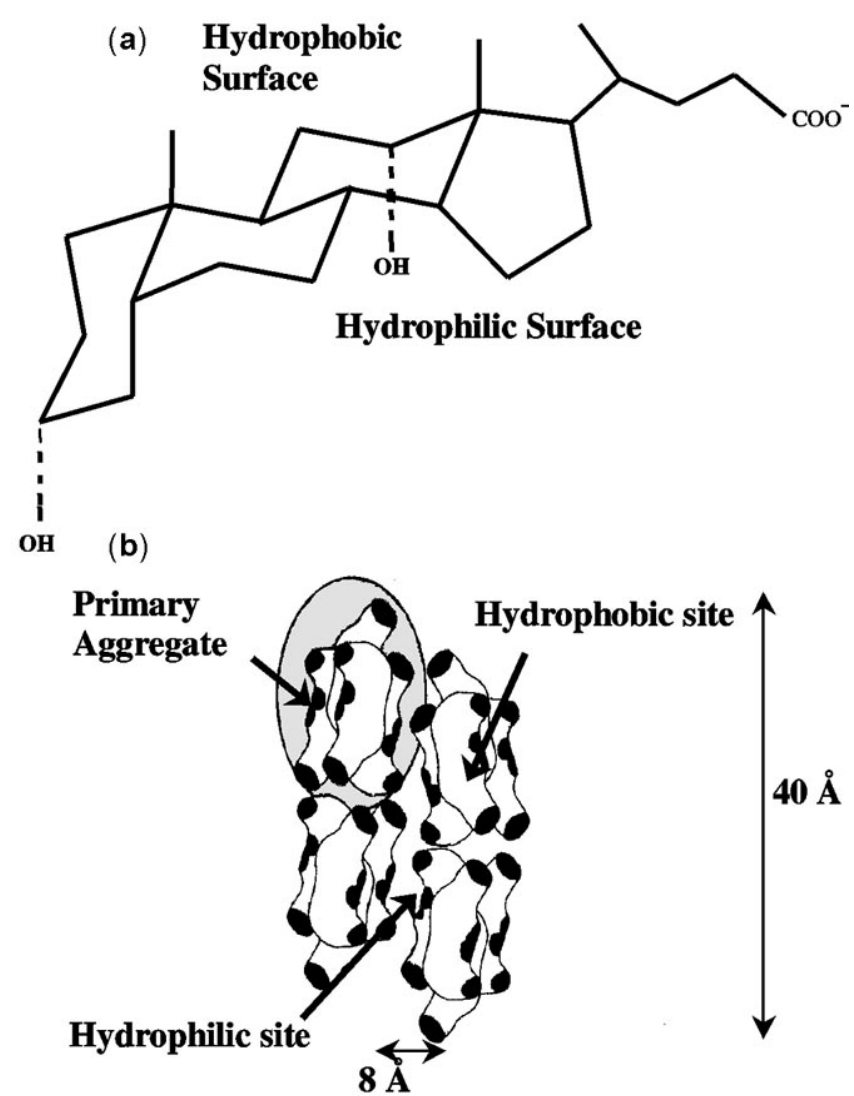

Scheme 2. Schematic representation of (a) Bile salt, $\mathrm{NaDC}$, (b) Secondary aggregate of $\mathrm{NaDC}$. 
decays were fitted using a Gaussian shape for the excitation pulse.

To fit the femtosecond data we used the long picosecond components and kept them fixed during fitting of femtosecond data. The picosecond components were detected using a set up in which the samples were excited at 375, 405 and $435 \mathrm{~nm}$ using picosecond diode laser (IBH Nanoleds) in an IBH Fluorocube apparatus. The emission was collected at a magic angle polarization using a Hamamatsu MCP photomultiplier (5000U-09). The time correlated single photon counting (TCSPC) set up consists of an Ortec 9327 CFD and a Tennelec TC 863 TAC. The data is collected with a PCA3 card (Oxford) as a multi-channel analyzer. The typical FWHM of the system response using a liquid scatterer is about $90 \mathrm{ps}$. The fluorescence decays were deconvoluted using IBH DAS6 software.

In order to study fluorescence anisotropy decay, the analyzer was rotated at regular intervals to get the parallel $\left(I_{\|}\right)$and perpendicular $\left(I_{\perp}\right)$ decays. The anisotropy function, $r(t)$ was calculated using the formula

$$
r(t)=\frac{I_{\| \mid}(t)-G I_{\perp}(t)}{I_{\| \mid}(t)+2 G I_{\perp}(t)}
$$

The $G$ value of our set up was determined using a probe whose rotational relaxation is very fast, e.g. C153 in methanol and was found to be 1.45 .

According to the Förster theory, the rate of FRET, $\mathrm{k}_{\mathrm{FRET}}$ is given by ${ }^{5 \mathrm{a}, \mathrm{b}, 8 \mathrm{a}, 10}$

$$
k_{\mathrm{FRET}}=\frac{1}{\tau_{D}^{0}}\left(\frac{R_{0}}{R_{D A}}\right)^{6},
$$

where, $\tau_{D}^{0}$ is the lifetime of the donor in the absence of acceptor. At a donor-acceptor distance $R_{\mathrm{DA}}=R_{0}$, the efficiency of energy transfer is $50 \%$ and $k_{\mathrm{FRET}}=$ $\left(1 / \tau_{D}\right)$. The Förster distance $R_{0}$ (in $\AA$ ) is given by, ${ }^{5 a, b, 6,8 a, 10}$

$$
R_{0}=0.211\left[\kappa^{2} n^{-4} Q_{D} J(\lambda)\right]^{1 / 6},
$$

where, $Q_{D}$ is the quantum yield of the donor in the absence of acceptor, $n$ is the refractive index of the medium $\left(\sim 1.4\right.$ for macromolecules in water),${ }^{10} \kappa^{2}$ is the orientation factor and $J(\lambda)$ is the spectral overlap between the donor emission and the acceptor absorption. $J(\lambda)$ is related to the normalized fluorescence intensity $\left(F_{D}\right)$ of the donor in the absence of the acceptor and the extinction coefficient of the acceptor $\left(\varepsilon_{A}\right)$ as, ${ }^{6,8 a, 10}$

$$
J(\lambda)=\frac{\int_{0}^{\infty} F_{D}(\lambda) \varepsilon_{A}(\lambda) \lambda^{4} \mathrm{~d} \lambda}{\int_{0}^{\infty} F_{D}(\lambda) \mathrm{d} \lambda}
$$

The value of $\kappa^{2}$ may vary from 0 (mutually perpendicular transition dipoles) to 4 (collinear dipoles). For $\kappa^{2}=0$, FRET is forbidden and no ultrafast component of FRET would be observed. The ultrafast FRET detected in this work obviously indicates a large value of $\kappa^{2}$. One can estimate the upper $\left(\kappa_{\max }^{2}\right)$ and lower $\left(\kappa_{\min }^{2}\right)$ limit of $\kappa^{2}$ following the recipe prescribed by Lakowicz and co-workers. ${ }^{10}$ The values of $\kappa_{\max }^{2}$ and $\kappa_{\min }^{2}$ are given by ${ }^{10}$

$$
\begin{aligned}
& \kappa_{\min }^{2}=\frac{2}{3}\left[1-\frac{\left(d_{D}^{x}+d_{A}^{x}\right)}{2}\right] \\
& \kappa_{\max }^{2}=\frac{2}{3}\left(1+d_{D}^{x}+d_{A}^{x}+3 d_{D}^{x} d_{A}^{x}\right)
\end{aligned}
$$

where, $d_{i}^{x}$ denotes the ratio of square root of the steady state fluorescence anisotropy $\left(r_{i}^{S S}\right)$ and the initial value of anisotropy $\left(r_{i}^{0}\right)$ in the anisotropy decay of the $i$ th species (donor or acceptor). However, the distance calculated using Förster model may vary by only about $\leq 20 \%$ in the range of values of $\kappa^{2}{ }^{6 b, 8 a}$ We therefore used $\kappa^{2}=2 / 3$ (random orientation) for the calculation of $R_{0}$.

In order to decompose the steady state emission spectrum into multiple spectra, we have assumed a log-normal spectral function e.g.

$$
I(\lambda)=I_{0} \exp \left\{-\ln 2\left[\ln \left\{1+2 b\left(\lambda-\lambda_{p}\right) / w\right\} / b\right]^{2}\right\},
$$

where, $I_{0}$ is peak height, $\lambda_{\mathrm{p}}$ is the emission maximum, $b$ is the asymmetric factor, $w$ denotes width of the spectrum.

\section{Results and discussions}

\subsection{Steady state absorption and emission spectra: $\lambda_{\text {ex }}$ dependence}

In pure water, $\mathrm{C} 153$ exhibits an absorption peak at $430 \mathrm{~nm}$ and an emission peak at $\sim 549 \mathrm{~nm}$ (figure 
1a). Solubility of $\mathrm{C} 153$ increases markedly on addition of $\mathrm{NaDC}$. The absorption and emission spectra of $\mathrm{C} 153$ in $105 \mathrm{mM} \mathrm{NaDC}$, are markedly blue shifted compared to those in water. In $105 \mathrm{mM}$ $\mathrm{NaDC}$ solution, the absorption maximum of $\mathrm{C} 153$ is at $424 \mathrm{~nm}$ and is blue shifted by $\sim 6 \mathrm{~nm}$ from the re-

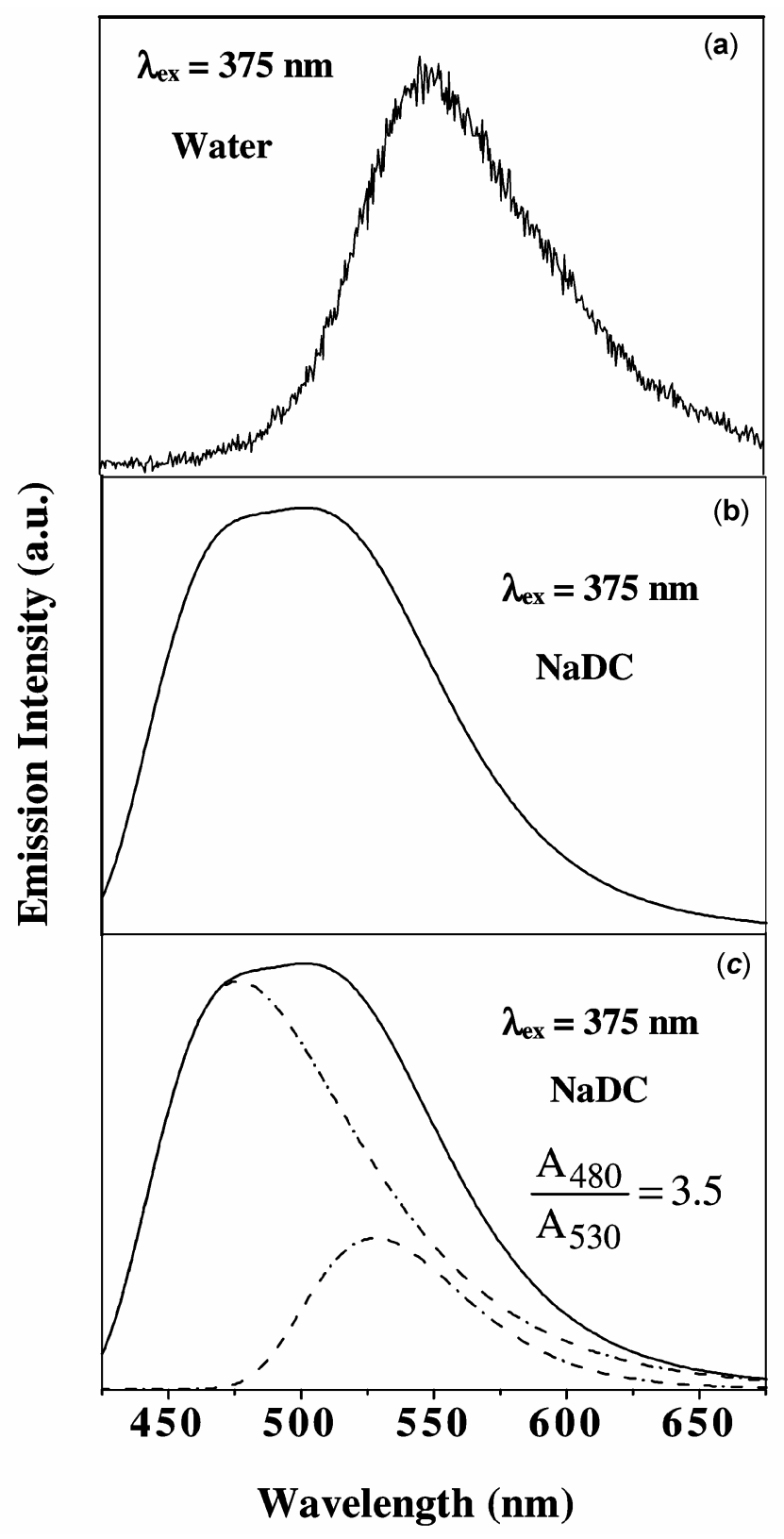

Figure 1. Emission spectra of C153 in (a) water $\left(\lambda_{\mathrm{ex}}=\right.$ $375-435 \mathrm{~nm}),(\mathbf{b}, \mathbf{c}) \mathrm{NaDC}\left(105 \mathrm{mM}, \lambda_{\mathrm{ex}}=375 \mathrm{~nm}\right.$, solid line). (c) Splitted spectrum (dotted line) of C153 in NaDC $\left(\lambda_{\mathrm{ex}}=375 \mathrm{~nm}\right)$ for the buried and exposed region. Ratio of the areas of emission spectra in polar region to that in non-polar is indicated (A denotes area under curve with emission maxima mentioned as subscript). ported $^{9}$ absorption maximum of $\mathrm{C} 153$ in water. The emission spectrum of $\mathrm{C} 153$ in $\mathrm{NaDC}$ is found to be much broader than that in water and shows a peak at
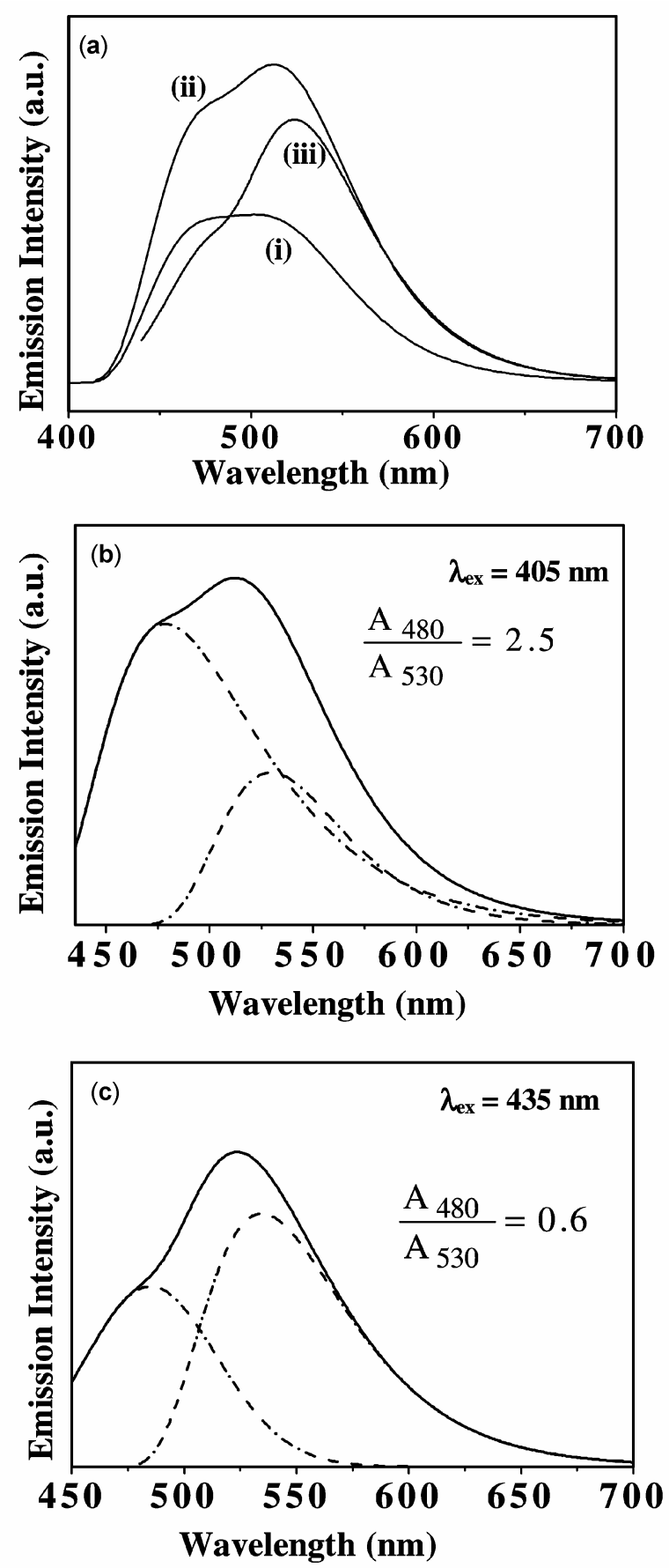

Figure 2. Emission spectra of $\mathrm{C} 153$ in $105 \mathrm{mM} \mathrm{NaDC}$ at (a) $\lambda_{\mathrm{ex}}=375 \mathrm{~nm}$ (i), $405 \mathrm{~nm}$ (ii) and $435 \mathrm{~nm}$ (iii). (b, c) Splitted spectrum of C153 in $105 \mathrm{mM} \mathrm{NaDC}$ (dotted line) at $\lambda_{\mathrm{ex}}=405 \mathrm{~nm}$ (b) and $435 \mathrm{~nm}$ (c), solid lines show the experimental spectra. Ratios of the areas of emission spectra in polar region to that in non-polar are indicated (A denotes area under curve with emission maxima mentioned as subscript). 
$\sim 520 \mathrm{~nm}$ and a prominent shoulder at $\sim 480 \mathrm{~nm}$ (figure $1 b, 2 a)$. With increase in $\lambda_{\text {ex }}$ from 375 to $435 \mathrm{~nm}$, the shape of the emission spectrum of $\mathrm{C} 153$ in $\mathrm{NaDC}$ changes markedly and displays a sharp decrease in the intensity of the shoulder region (figure 2a). The broadness of the emission spectrum and the $\lambda_{\text {ex }}$ dependence suggest presence of multiple locations of $\mathrm{C} 153$ inside the NaDC aggregate. The emission spectrum of $\mathrm{C} 153$ in NaDC may be resolved as a superposition of two spectra one with maximum at $480 \mathrm{~nm}$ and another with maximum $\sim 530 \mathrm{~nm}$ (figures $1 \mathrm{c}$ and $2 \mathrm{~b}-\mathrm{c}$ ). In summary, in the $\mathrm{NaDC}$ aggregate C153 molecules are distributed in two locations with distinctly different emission maximum (480 and $530 \mathrm{~nm}$ ). From the reported emission maxima of C153 in different solvents ${ }^{9}$ the $480 \mathrm{~nm}$ emission peak corresponds to a relatively non-polar hydrophobic location whose polarity is intermediate between cyclohexane and ethyl acetate. The $530 \mathrm{~nm}$ emission peak of C153 may arise from a polar and hydrophilic region which is similar to ethanol. The relative intensity (area) of the two emission spectra $\left(A_{480} / A_{530}\right)$ decreases from 3.5 at $\lambda_{\text {ex }}=375 \mathrm{~nm}$ to 0.6 at $\lambda_{\mathrm{ex}}=435 \mathrm{~nm}$. It is obvious that with increase in $\lambda_{\mathrm{ex}}$ contribution of the polar (exposed) region (maximum at $530 \mathrm{~nm}$ ) increases with a concomitant decrease in the contribution of the non-polar (buried) region (peak at $480 \mathrm{~nm}$ ).

The absorption maximum of rhodamine $6 \mathrm{G}$ (R6G) in $\mathrm{NaDC}$ is observed to be at $537 \mathrm{~nm}$. This is red shifted by $11 \mathrm{~nm}$ from that of R6G in water. ${ }^{8 a}$ The emission maximum $(567 \mathrm{~nm})$ of R6G in bile salt aggregate is found to be red shifted from that $(550 \mathrm{~nm})$ in water. The emission maximum of $\mathrm{R} 6 \mathrm{G}$ in $105 \mathrm{mM}$ does not display any $\lambda_{\text {ex }}$ dependence. This indicates that the cationic dye (R6G) is predominantly localized in the polar and exposed site of $\mathrm{NaDC}$

\section{$3.2 \lambda_{\text {ex }}$ dependence of spectral overlap and FRET from C153 to $R 6 G$}

Addition of the acceptor (R6G) to a solution of C153 in $105 \mathrm{mM} \mathrm{NaDC}$ causes a marked decrease in the emission intensity of the donor (figure 3 ) because of FRET from C153 to R6G. Interestingly, as shown in figure 3 , the extent of quenching of the donor emission depends on $\lambda_{\text {ex }}$. It is observed that the extent of quenching of donor emission (i.e. FRET) is maximum for a long $\lambda_{\text {ex }}(435 \mathrm{~nm}$, figure $3 \mathrm{c})$ and minimum for a short $\lambda_{\mathrm{ex}}(375 \mathrm{~nm}$, figure $3 \mathrm{a})$.
This may be explained as follows. As noted earlier, the donor $(\mathrm{C} 153)$ is distributed over the polar and non-polar site while the $\mathrm{R} 6 \mathrm{G}$ is preferentially local-
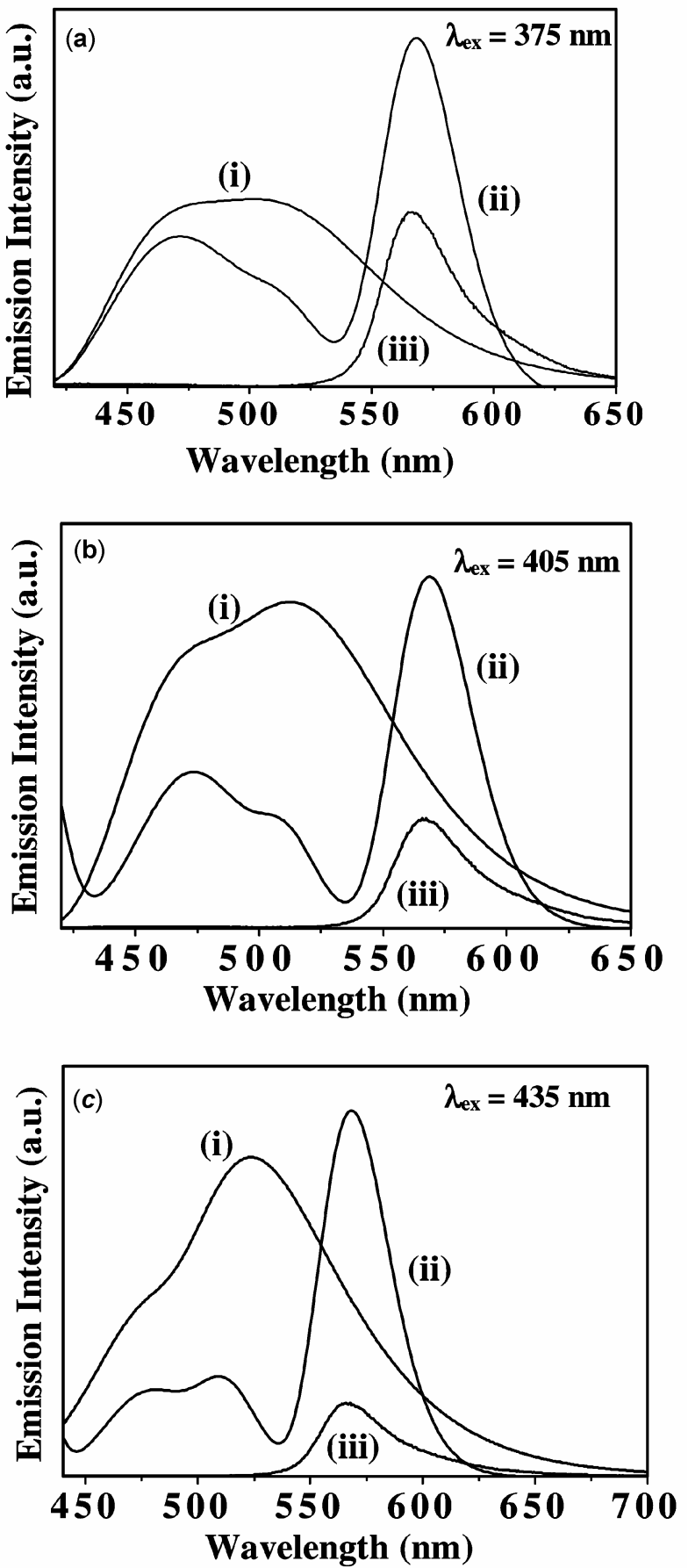

Figure 3. Emission spectra of C153 $(40 \mu \mathrm{M})$ in $105 \mathrm{mM}$ $\mathrm{NaDC}$ in the absence (i) and presence (ii) of $40 \mu \mathrm{M}$ R6G at $\lambda_{\mathrm{ex}}=375$ (a), 405 (b) and $435 \mathrm{~nm}$ (c); while (iii) in each case denotes the emission spectrum of R6G $(40 \mu \mathrm{M})$ in $105 \mathrm{mM} \mathrm{NaDC}$. 
Table 1. Energy transfer parameters for C153-R6G pair in $105 \mathrm{mM} \mathrm{NaDC}$.

\begin{tabular}{|c|c|c|c|c|c|}
\hline \multicolumn{2}{|c|}{$J(\lambda)^{*}\left(\mathrm{M}^{-1} \mathrm{~cm}^{-1} \mathrm{~nm}^{4}\right)$} & \multicolumn{2}{|c|}{$R_{0}(\AA)$} & \multicolumn{2}{|c|}{ Steady state efficiency of FRET $\left(\varepsilon_{s}^{*}\right)$} \\
\hline Peak 1 (buried) & Peak 2 (exposed) & Peak 1 (buried) & Peak 2 (exposed) & Peak 1 & Peak 2 \\
\hline $1.9 \times 10^{15}$ & $3.9 \times 10^{15}$ & $50 \pm 1$ & $56 \pm 1$ & $0 \cdot 15$ & $0 \cdot 60$ \\
\hline
\end{tabular}

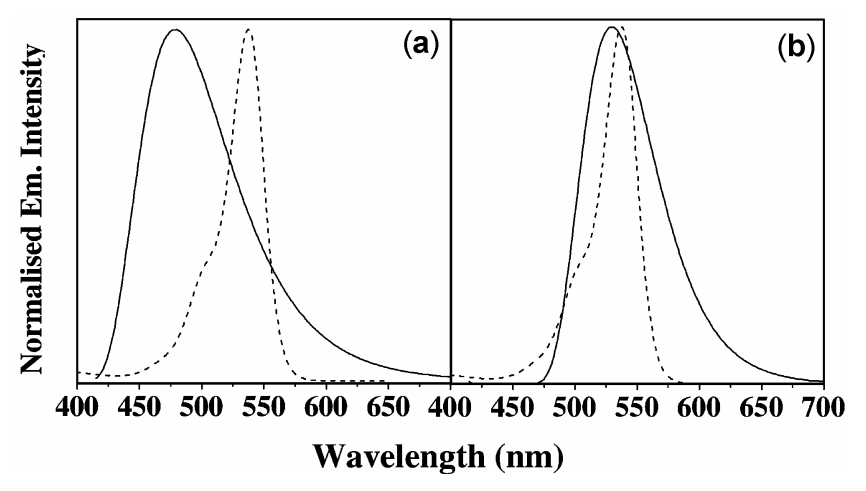

Figure 4. Spectral overlap of donor (C153) emission (solid line) with acceptor R6g absorption (dotted line) in $105 \mathrm{mM} \mathrm{NaDC}$ for the buried (a) and the exposed (b) region (donor emission obtained from the spectral splitting).

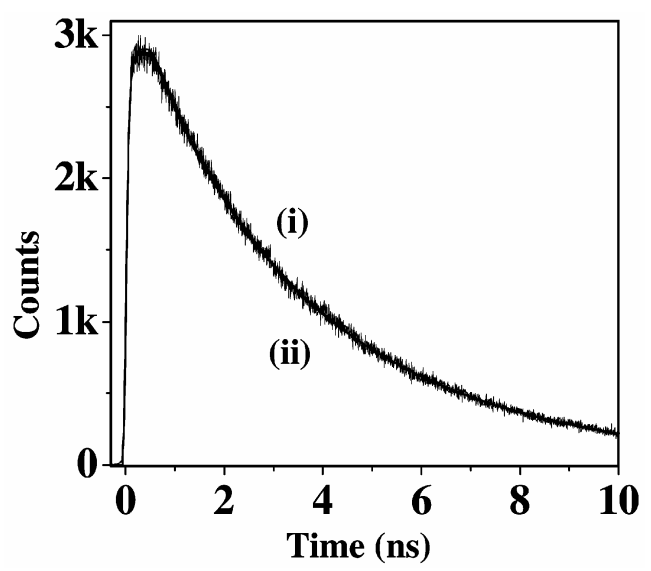

Figure 5. Picosecond fluorescence transient $\left(\lambda_{\mathrm{em}}=\right.$ $465 \mathrm{~nm}$ ) of $40 \mu \mathrm{M} \mathrm{C} 153$ (donor) in $105 \mathrm{mM} \mathrm{NaDC}$ in the absence (i) and in the presence (ii) of $40 \mu \mathrm{M}$ R6G $\left(\lambda_{\mathrm{ex}}=405 \mathrm{~nm}\right)$.

ized in the polar site. A long $\lambda_{\text {ex }}(435 \mathrm{~nm})$ selects the polar site where the donor and the acceptor are close to each other and hence, displays very efficient FRET. For a short $\lambda_{\text {ex }}(375 \mathrm{~nm})$ donors in the nonpolar region are excited which are far from the acceptor and hence, efficiency of FRET diminishes.
Table 2. Femtosecond decay parameters of R6G $\left(40 \mu \mathrm{M}, \lambda_{\mathrm{em}}=570 \mathrm{~nm}\right)$ in the absence of C153 at different $\lambda_{\text {ex. }}$.

\begin{tabular}{lccc}
\hline Medium & $\lambda_{\text {ex }}(\mathrm{nm})$ & $\tau_{1}^{*}\left(a_{1}\right)(\mathrm{ps})$ & $\tau_{2}^{*}\left(a_{2}\right)(\mathrm{ps})$ \\
\hline NaDC $(105 \mathrm{mM})$ & 375 & - & $6900(1 \cdot 00)$ \\
& 405 & - & $6500(1 \cdot 00)$ \\
& 435 & $100(0 \cdot 13)$ & $6800(0 \cdot 87)$ \\
\hline
\end{tabular}

$* \pm 10 \%$

In order to understand the $\lambda_{\mathrm{ex}}$ dependence of FRET we studied the spectral overlap of the acceptor absorption with the donor emission for the buried and the exposed regions. Figure 4 shows the spectral overlap in these two cases. The efficiency $\left(\varepsilon_{\mathrm{s}}\right)$ of FRET was calculated from the steady state emission intensities. If $I_{D A}$ and $I_{D}$, denote the emission intensity of the donor in the presence and absence of the acceptor, the efficiency of FRET is given by, $\mathcal{E}_{S}=1-\left(I_{D A} / I_{D}\right){ }^{8 \mathrm{a}, 10}$

The efficiency of FRET $\left(\varepsilon_{s}\right)$, overlap integral $(J(\lambda))$ and the Forster distance $\left(R_{0}\right)$ for the two sites of the donor at different $\lambda_{\text {ex }}$ are summarized in table 1 . It is readily seen that the efficiency of FRET for the buried region (donor emission maximum $\sim 480 \mathrm{~nm}$ ) is much lower than that for the exposed region (donor emission maximum $\sim 530 \mathrm{~nm}$ ). For instance, at $\lambda_{\mathrm{ex}}=375 \mathrm{~nm}$ the efficiency for the buried region $(0 \cdot 15)$ is about 4 times smaller than that $(0 \cdot 6)$ for the exposed site. With increase in $\lambda_{\text {ex }}$, the relative contribution of the exposed site increases (figures 1 and 2) and this causes an increase in the efficiency of FRET.

\subsection{Time resolved studies of FRET from C153 to $R 6 G$ in bile salt aggregate}

3.3a Picosecond studies of donor decay: FRET is commonly monitored by shortening of the donor life time. ${ }^{10}$ Figure 5 shows picosecond fluorescence decays of the donor (C153) at $465 \mathrm{~nm}$ in $105 \mathrm{mM}$ $\mathrm{NaDC}$ in the absence and presence of acceptor 
Table 3. Excitation wavelength $\left(\lambda_{\mathrm{ex}}\right)$ dependence of rise of acceptor (40 $\mu \mathrm{M}$ $\mathrm{R} 6 \mathrm{G})$ in the presence of $40 \mu \mathrm{M}$ donor (C153) in $105 \mathrm{mM} \mathrm{NaDC}$ at $\lambda_{\mathrm{em}}=570 \mathrm{~nm}$.

\begin{tabular}{llcl}
\hline$\lambda_{\mathrm{ex}}(\mathrm{nm})$ & $\tau_{1} *\left(a_{1}\right)(\mathrm{ps})$ & $\tau_{2} *\left(a_{2}\right)(\mathrm{ps})$ & $\tau_{3} *\left(a_{3}\right)(\mathrm{ps})$ \\
\hline 375 & $4(-0 \cdot 10,3 \%)$ & $3700(-3 \cdot 06,97 \%)$ & $7000(4 \cdot 16)$ \\
405 & $4(-0 \cdot 12,13 \%)$ & $3700(-0 \cdot 83,87 \%)$ & $7000(1 \cdot 95)$ \\
435 & $4(-0 \cdot 13,40 \%)$ & $3700(-0 \cdot 20,60 \%)$ & $7000(1 \cdot 33)$ \\
\hline
\end{tabular}

\section{$* \pm 10 \%$}

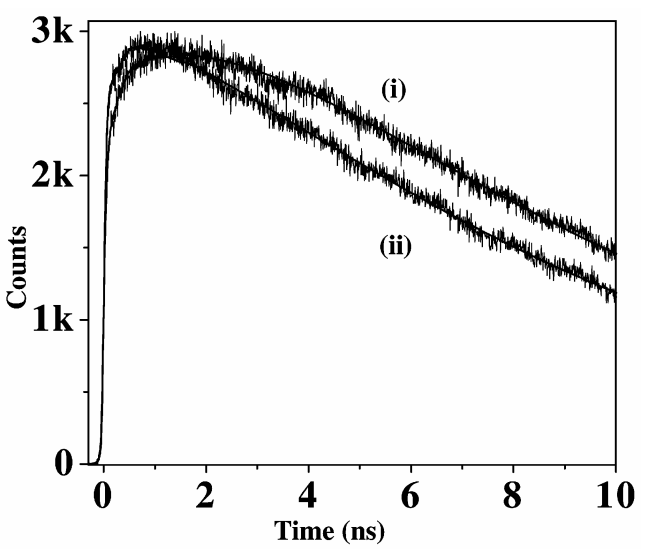

Figure 6. Picosecond fluorescence decays of acceptor R6G (at $\lambda_{\mathrm{em}}=570 \mathrm{~nm}$ ) in $105 \mathrm{mM} \mathrm{NaDC}$ in the presence of donor (C153) for (i) $\lambda_{\mathrm{ex}}=375 \mathrm{~nm}$ and (ii) $\lambda_{\mathrm{ex}}=435 \mathrm{~nm}$.

(R6G) at $\lambda_{\mathrm{ex}}=405 \mathrm{~nm}$. It is readily seen that in $105 \mathrm{mM} \mathrm{NaDC}$, addition of the acceptor (R6G) does not affect the average decay time of $\mathrm{C} 153$. This result which is in apparent contradiction with steady state emission intensities may be explained as follows. The fluorescence decay is dominated by the unquenched (non-FRET) donors in a bile salt aggregate with no acceptor. ${ }^{6,8 a, 12}$ The life time of the donor molecules which have an acceptor in the immediate vicinity in the same micelle is often too short to measure using a picosecond set up. Thus, the picosecond study of the donor lifetime incompletely describes FRET from C153 to R6G in $\mathrm{NaDC}$

3.3b Picosecond studies of acceptor fluorescence: In order to determine the ultrafast components of FRET we studied the rise time of the acceptor (R6G) emission. ${ }^{6,8 a}$ According to Tachiya ${ }^{13 a, b}$ the rise of the acceptor emission is given by $-\exp [-n(1-\exp (-$ $\left.k_{\text {FRET }} q t\right)$ ] where $\mathrm{n}$ is the average number of acceptor per micelle. For times shorter than $1 / k_{\text {FRET }}<1$, the initial ultrafast rise is given by $-\exp \left(-k_{\mathrm{FRET}} t\right)$ (since in this case $n \sim 1$ ).

The fluorescence transients of the acceptor (R6G) were studied at an emission wavelength $\left(\lambda_{\mathrm{em}}\right)$
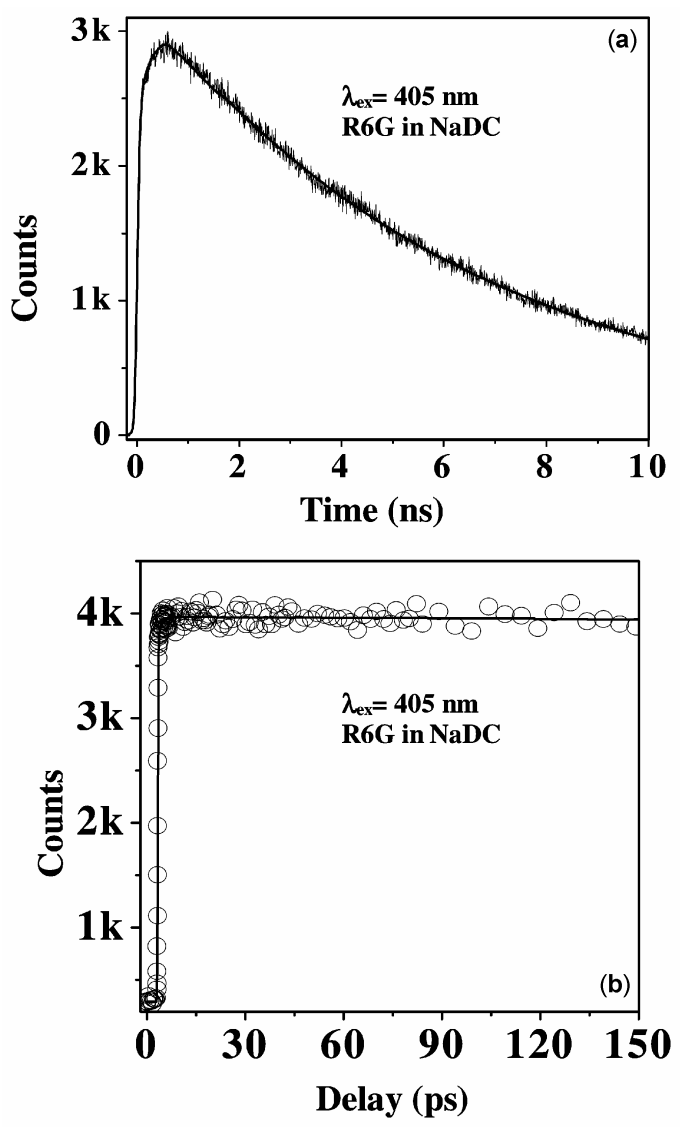

Figure 7. Picosecond (a) and femtosecond (b) fluorescence transient $\left(\lambda_{\mathrm{em}}=570 \mathrm{~nm}\right)$ of $40 \mu \mathrm{M}$ R6G in $105 \mathrm{mM}$ $\mathrm{NaDC}$ in the absence of $\mathrm{C} 153$ (donor) $\left(\lambda_{\mathrm{ex}}=405 \mathrm{~nm}\right)$.

$570 \mathrm{~nm}$ where the contribution of the quenched donor emission is negligible. In $105 \mathrm{mM} \mathrm{NaDC}$, acceptor (R6G) shows a single exponential decay $\left(\lambda_{\mathrm{em}}=\right.$ $570 \mathrm{~nm}$ ) with no rise components in the absence of the donor (C153) (figure 6, table 2). In the presence of the donor, in $\mathrm{NaDC}$, the picosecond transient of the acceptor (R6G) at $570 \mathrm{~nm}$ shows a rise time of 3700 ps (figure 6 and table 3 ).

3.3c Femtosecond study of the acceptor transients: For the detection of the ultrafast components of FRET, we used a femtosecond up-conversion set up. In the absence of the donor no rise component is observed in the acceptor emission (figure 7, table 2). 
Using the femtosecond set up, we detected both ultrafast rise time of the acceptor emission (figure 8) and an ultrafast decay component of the donor emission in the presence of the acceptor. Shortening of donor life time and the appearance of growth in acceptor's decay unambiguously confirms ultrafast FRET from donor (C153) to an acceptor (R6G) in $\mathrm{NaDC}$.

Figure 8 shows the femtosecond rise of the acceptor $(\mathrm{R} 6 \mathrm{G})$ in the presence of donor $(\mathrm{C} 153)$ at an emission wavelength of $570 \mathrm{~nm}$ in $105 \mathrm{mM} \mathrm{NaDC}$ solution at different $\lambda_{\mathrm{ex}}$. For all $\lambda_{\mathrm{ex}}$, we have detected an ultrafast (4 ps) rise component of the acceptor emission (i.e. of FRET) in addition to 3700 ps component (table 3). As shown in table 3, the relative contribution of the ultrafast rise component increases markedly with increase in $\lambda_{\text {ex }}$. With increase in excitation wavelength from 375 to $435 \mathrm{~nm}$, contribution of the $3700 \mathrm{ps}$ rise time decreases from 97 to $60 \%$, respectively (table 3 ).

\subsection{Donor-acceptor distances: $\lambda_{e x}$ dependence of FRET}

The donor-acceptor distances $\left(R_{D A}\right)$ corresponding to the FRET components $\left(=1 / k_{\mathrm{FRET}}\right) 4 \mathrm{ps}$ and $3700 \mathrm{ps}$ were determined using equation (2) and the calculated values of $R_{0}$. The $4 \mathrm{ps}$ component corresponds to $R_{\mathrm{DA}}=17 \AA$ which is close to the sum of the radii of the donor and the acceptor. The ionic acceptor resides preferentially in the polar region. Thus the $4 \mathrm{ps}$ component of FRET arises from FRET between the donor and the acceptor, both in the polar region. Obviously, with increase in $\lambda_{\mathrm{ex}}$, contribution of the donors in the polar region increases. As a result, with increase in $\lambda_{\mathrm{ex}}$, contribution of the 4 ps compo-

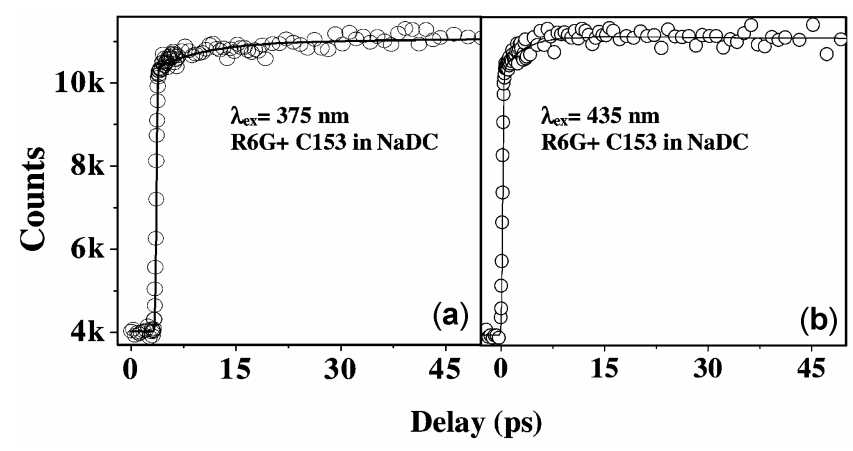

Figure 8. Femtosecond fluorescence transients of R6G (at $\lambda_{\mathrm{em}}=570 \mathrm{~nm}$ ) in $105 \mathrm{mM} \mathrm{NaDC}$ in the presence of donor (C153) for (a) $\lambda_{\mathrm{ex}}=375 \mathrm{~nm}$ and (b) $\lambda_{\mathrm{ex}}=435 \mathrm{~nm}$. nent increases from $3 \%$ at $\lambda_{\text {ex }}=375 \mathrm{~nm}$ to $40 \%$ at $\lambda_{\text {ex }}=435 \mathrm{~nm}$ (table 3$)$.

The 3700 ps component of FRET corresponds to $R_{D A}=48 \AA$. Thus it arises from donor which are residing in the non-polar region far from the ionic acceptor. With increase in $\lambda_{\mathrm{ex}}$, contribution of the nonpolar region decreases and hence, contribution of the $3700 \mathrm{ps}$ component decreases from $97 \%$ at $\lambda_{\mathrm{ex}}=$ $375 \mathrm{~nm}$ to $60 \%$ at $\lambda_{\mathrm{ex}}=435 \mathrm{~nm}$ (table 3 ).

The donor molecules diffuse over a distance $\left(2 D_{t} \tau_{\mathrm{FRET}}\right)^{1 / 2}$ in the timescale of FRET $\left(\tau_{\mathrm{FRET}}\right)$. For organic molecules in a micelle the translational diffusion $D_{t}$ is of the order $0 \cdot 5-50 \AA^{2} / \mathrm{ns}^{14-16}$ For $105 \mathrm{mM}$ $\mathrm{NaDC}$ aggregate the ultrafast component of FRET: $4 \mathrm{ps}$ and the long $3700 \mathrm{ps}$ component correspond to diffusion lengths of $1.3 \AA$ and $38.5 \AA$, respectively. Obviously, diffusion of donors in the 4 ps time scale of FRET is smaller than molecular dimensions. However, for the 3700 ps component one can not neglect diffusion of donors.

\subsection{Excitation wavelength $\left(\lambda_{\text {ex }}\right)$ dependence of anisotropy decay of $\mathrm{Cl} 53$}

In bulk water, the time constant of fluorescence anisotropy decay of $\mathrm{C} 153$ is $\sim 100 \mathrm{ps}^{1{ }^{11}}$ The fluores-

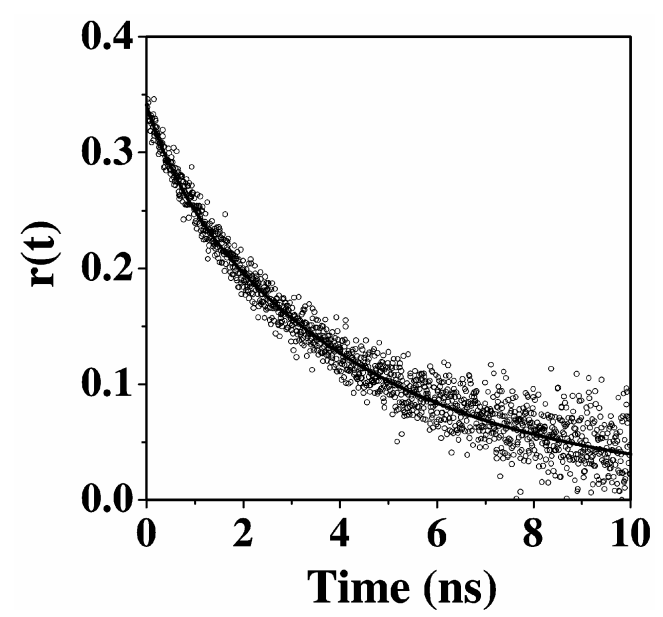

Figure 9. Fluorescence anisotropy decay of C153 in $105 \mathrm{mM} \mathrm{NaDC}$ at $\lambda_{\mathrm{ex}}=405 \mathrm{~nm}\left(\lambda_{\mathrm{em}}=465 \mathrm{~nm}\right)(\mathrm{O})$. The points denote the actual values of anisotropy and the solid lines denote the best fit to the experimental data.

Table 4. Parameters of anisotropy decay of C153 in $\mathrm{NaDC}(105 \mathrm{mM})$ for $\lambda_{\mathrm{ex}}=405 \mathrm{~nm}$.

\begin{tabular}{lccc}
\hline$\lambda_{\mathrm{em}}(\mathrm{nm})$ & $r_{0}$ & $\tau_{\text {fast }}(\mathrm{ps})\left(a_{\text {fast }}\right)$ & $\tau_{\text {slow }}(\mathrm{ps})\left(a_{\text {slow }}\right)$ \\
\hline 465 & 0.34 & $600 \pm 50(0 \cdot 13)$ & $4200 \pm 200(0.87)$ \\
\hline
\end{tabular}


cence anisotropy decay of $\mathrm{C} 153$ in bile salt aggregate (at blue side of the peak, $465 \mathrm{~nm}$, figure 9) is found to be much slower and is fitted to a biexponential function,

$$
r(t)=r_{0}\left[\beta \exp \left(-t / \tau_{\text {slow }}\right)+(1-\beta) \exp \left(-t / \tau_{\text {fast }}\right)\right] .
$$

The high value of initial anisotropy $\left(r_{0}=0.34\right)$ in bile salt aggregate (table 4 ) suggests that our picosecond set up captures almost the entire rotational dynamics in this case. For $\lambda_{\mathrm{ex}}=405 \mathrm{~nm}$, the anisotropy decay of $\mathrm{C} 153$ in $\mathrm{NaDC}$ is described by two decay components of $600 \mathrm{ps}(13 \%)$ and $4200 \mathrm{ps}$ (87\%) (figure 9, table 4). The anisotropy decay of $\mathrm{C} 153$ in NaDC does not show appreciable dependence on $\lambda_{\text {ex }}$.

\section{Conclusion}

This work demonstrates that the FRET in bile salt aggregate occurs on multiple time scale-4 and 3700 ps. The 4 ps component is assigned to both donor and acceptor residing at close proximity in the polar region $\left(R_{\mathrm{DA}}=17 \AA\right)$. The $3700 \mathrm{ps}$ component arises due to FRET from a donor in the non-polar region to an acceptor in the polar region $\left(R_{\mathrm{DA}}=\right.$ $48 \AA$ ). It is further shown that with increase in $\lambda_{\mathrm{ex}}$, contribution of FRET from the donor in the polar region (4 ps component) increases and that due to donor in the non-polar region (3700 ps component) decreases.

\section{Acknowledgements}

The authors thank the Department of Science and Technology (DST), (IR/11/CF-01/2002 and J. C. Bose Fellowship) and Council of Scientific and Industrial Research (CSIR) for generous research grants. U M, S G, D K D, A A and S D thank CSIR for awarding fellowships. K B thanks Prof. B Bagchi and M Tachiya for many useful suggestions.

\section{References}

1. (a) Small D M 1971 The bile acid (Plenum: New York), vol 1, p. 302; (b) O'connor C J and Wallace R G $1985 A d v$. Colloid Interface Sci. 22 1; (c) Borgtstorm B, Barrowman J A and Lindstorm M 1985 In Sterols and bile acid (eds) H Danielsson and J Sjoval (Amsterdam: Elsevier)

2. (a) Leggio C, Galantini L and Zaccarelli E $2005 \mathrm{~J}$. Phys. Chem. B109 23857; (b) Hjelm R P, Schteingert
C D, Hofman A F and Thiagrajan P 2000 J. Phys. Chem. B104 197; (c) Santhanlakshmi J, Shantha Lakshmi G, Aswal V K and Goyal P S 2001 Proc. Indian Acad. Sci., Chem. Sci. 113 55; (d) Lopez F, Samseth J, Mortensen K, Rosenquist E and Rouch J 1996 Langmuir 12 618; (e) Esposito G, Giglio E, Pavel N $\mathrm{V}$ and Zanobi A 1987 J. Phys. Chem. 91356

3. (a) Megyesi M and Biczok L 2007 J. Phys. Chem. B111 5635; (b) Yihwa C, Quina F H and Bohne C 2004 Langmuir 20 9983; (c) Waissbluth O L, Morales M C and Bohne C 2006 J. Photochem. Photobiol. 82 1030; (d) Gouin S and Zhu X X 1998 Langmuir. 14 4025; (e) Ju C and Bohne C 1996 J. Phys. Chem. 1003847

4. Sen S, Dutta P, Mukherjee S and Bhattacharyya K 2002 J. Phys. Chem. B $\mathbf{1 0 6} 7745$

5. (a) Wong K F, Bagchi B and Rossky P J $2004 \mathrm{~J}$. Phys. Chem. A108 5752; (b) Srinivas G and Bagchi B 2001 J. Phys. Chem. B105 9370; (c) Schuler B, Lipman E A, Steinbach P J, Kumke M and Eaton W A 2005 Proc. Natl. Acad. Sci. USA 102 2754; (d) Kuzmenkina E V, Heyes C D and Nienhaus G U 2005 Proc. Natl. Acad. Sci. USA 102 15471; (e) Cotlet M, Vosch T, Habuchi S, Weil T, Mullen K, Hofkens J and Schryver F De 2005 J. Am. Chem. Soc. 127 9760; (f) Goldman E R, Medintz I L, Whitley J L, Hayhurst A, Clapp A R, Uyeda H T, Deschamps J R, Lassman M E and Mattoussi H $2005 \mathrm{~J}$. Am. Chem. Soc. 127 6744

6. (a) Ghosh S, Dey S, Adhikari A, Mandal U and Bhattacharyya K 2007 J. Phys. Chem. B111 7085; (b) Mondal S K, Ghosh S, Sahu K, Mandal U and Bhattacharyya K 2006 J. Chem. Phys 125224710

7. (a) Lakowicz J R 1984 Biochemistry 23 3013; (b) Demchenko A P 1982 Biophys. Chem. 15 101; (c) Mukherjee S and Chattopadhyay A 2005 Langmuir 21287

8. (a) Sahu K, Ghosh S, Mondal S K, Ghosh B C, Sen P, Roy D and Bhattacharyya K 2006 J. Chem. Phys. 125 044714; (b) Satoh T, Okuno H, Tominaga $\mathrm{K}$ and Bhattacharyya K 2004 Chem. Lett. 33 1090; (c) Sen, $\mathrm{P}$, Satoh T, Bhattacharyya K and Tominaga K 2005 Chem. Phys. Lett. 411 339; (d) Sen P, Ghosh S, Mondal S K, Sahu K, Roy D, Bhattacharyya K and Tominaga K 2006 Chem. Asian. J. 1188

9. Jones II G, Jackson W R, Choi C-Y and Bergmark W R 1985 J. Phys. Chem. 89294

10. Lakowicz J R 2006 Principles of fluorescence spectroscopy (New York: Springer), Chap. 9, 13, 14 and 15,3 rd edn

11. Hazra P, Chakrabarty D, Chakraborty A and Sarkar N 2004 Biochem. Biophys. Res. Commun. 314543

12. Kenney-Wallace G A, Flint $\mathrm{J} \mathrm{H}$ and Wallace S C 1975 Chem. Phys. Lett. 3271

13. (a) Tachiya M 1975 Chem. Phys. Lett. 33 289; (b) Tachiya M 1982 J. Chem. Phys. 76340

14. Matzinger S, Weidemaier K and Fayer M D 1997 Chem. Phys. Lett. 276274

15. Quitevis E L, Marcus A H and Fayer M D $1997 \mathrm{~J}$. Phys. Chem. 975762

16. Sen P, Ghosh S, Sahu K, Mandal S K, Roy D and Bhattacharyya K 2006 J. Chem. Phys. 124204905 